\title{
Letra de cambio y pagaré: ¿títulos valores de uso meramente mercantil 0 de uso común o público?
}

\author{
José Guillermo Martínez Díaz \\ Docente Utec \\ jose.martinez@utec.edu.sv \\ Recibido: 22/11/2016 - Aceptado: 26/02/2017
}

\begin{abstract}
Resumen
El objetivo del presente artículo consiste en que, desde el punto de vista legal, los títulos valores son documentos meramente mercantiles, con lo cual se confirma que hablamos de un documento empresarial, ya que su importancia recae en hacer más ágiles las transacciones mercantiles y el flujo comercial; pero en la realidad el uso de los títulos valores se ha desvirtuado de lo establecido en la ley, pues se ha vuelto tan común que no solamente a nivel mercantil se utilizan, sino cualquier persona que tenga un compromiso crediticio en el mercado informal o particular los utiliza, con el fin de asegurarse el pago a futuro, o sea, utilizan los títulos valores como una simple garantía de pago, por lo que nos planteamos lo siguiente: letra de cambio y pagaré: ¿títulos valores de uso meramente mercantil o de uso común o público?
\end{abstract}

\section{Palabras clave}

Pagares - legislación - El Salvador, escrituras de propiedad, sistemas de crédito, crédito, cartas de crédito, documentos negociables, derecho comercial.

\section{Abstract}

This article focuses on the fact that from the legal point of view, securities are merely trade documents, which confirms that we are making reference to a business document since its relevance relies in making both the commercial transactions and the commercial flow more agile. In reality, the use of securities has lost value from what has been established by law; it has become so common that they are not only used at a trade level; any person with a financial commitment in the informal or individual market uses them with the purpose of guaranteeing a future payment. Securities are used as a mere payment guarantee, therefore the question: Bills of exchange and promissory notes: securities for mere mercantile use, common use or public use? .

\section{Keywords}

Promissory notes - legislation - El Salvador, deeds of ownership, credit systems, credit, letters of credit, negotiable instruments, Commercial law.

\footnotetext{
${ }^{1}$ Docente de la Facultad de Derecho de la Universidad Tecnológica de El Salvador (Utec). Especialista en Derecho Mercantil. Abogado y notario.
} 


\section{Introducción}

En nuestro país, los títulos valores en general son utilizados en gran medida en materia mercantil/empresarial, pero la letra de cambio y el pagaré también se utilizan a nivel social, ya que estos documentos solo los conocemos para garantizar una deuda o un crédito. En ese ámbito, ya nuestro Código de Comercio nos menciona que los títulos valores son utilizados en materia mercantil, o sea, los utilizados por el comerciante mercantil o empresario social o individual (como lo dicta la doctrina moderna), pero existen también en ese orden dos títulos valores que se utilizan de manera común o general, como la letra de cambio y el pagaré. En ese orden de utilización común, es de notar que dichos títulos se han considerado como documentos cartulados de venta común; en cualquier tienda o librería del país pueden ser adquiridos. En ese orden, podemos preguntarnos: ¿la letra de cambio y el pagaré son títulos valores de uso exclusivo mercantil o de uso común o público?

Para empezar, hay que establecer que los títulos valores son contemplados como títulos mercantiles reconocidos por nuestra legislación, específicamente por el código de Comercio, pero a la vez debemos saber qué son los títulos valores. En este caso, el concepto por excelencia es el dado por el jurisconsulto italiano César Vivante, quien define al título valor o título de crédito como "el documento necesario para ejercer el derecho literal y autónomo expresado en el mismo" (Vivante, 1936). Esta definición hace especial énfasis en la relación necesaria que existe entre el título y los derechos que en él se mencionan, ya que las obligaciones contenidas en un título valor pueden ser ejercitadas legítimamente solo mediante su posesión. Así mismo, nuestro Código de Comercio, en el artículo 5, romano $3^{\circ}$, Ios define como "cosas mercantiles"; y el artículo 623 contiene el concepto legal retomado de Vivante, en el sentido que son títulos valores los documentos necesarios para hacer valer el derecho literal y autónomo que en ellos se consigna.

En ese caso podemos establecer que la letra de cambio y el pagaré son documentos necesarios que le sirven al comerciante mercantil o empresario, y no de uso común o público, ya que cuando referimos que son cosas mercantiles, y más específicamente que son cosas típicamente mercantiles, son exclusivamente de uso del empresario; nuestra legislación no nos menciona que sean de uso público, que cualquier persona pueda utilizarlos; pero en la realidad, y ya en la práctica, tanto la letra de cambio como el pagaré son utilizados por personas naturales, no importa que quien utilice estos títulos valores no sea empresario; pues, sin serlo, la persona que hace operaciones con títulos valores se vuelve empresario de forma circunstancial.

Otra de las ideas que se tiene de los títulos valores es lo que nos plantea Messineo (Espinoza, 1995), quien prefirió la utilización de la expresión "papel valor", y explica que "papel alude al documento, y valor, al diverso derecho, siempre de contenido patrimonial, que puede contenerse en él". Así mismo, tenemos que, de los títulos valores, su principal función es la de facilitar el tráfico jurídico, así como la circulación de los bienes, pues en la actualidad constituyen un elemento imprescindible del tráfico mercantil, por eso es que está claro que todos los títulos valores sin excepción son documentos mercantiles, por lo tanto no debieran de ser utilizados por cualquier persona; pero eso es lo irreal: en la práctica, específicamente, tanto la letra de cambio como el pagaré son utilizados por indistintas personas, y son utilizados como documentos que garantizan una deuda simple y no un crédito o transacción mercantil. Es el colmo que dichos títulos valores sean comercializados en cualquier librería o en cualquier tienda de colonia; por lo que se rompe el principio rector del artículo 5 del Código de Comercio, que plantea que los títulos valores son cosas mercantiles, como anteriormente se ha planteado; son de uso exclusivo del comerciante mercantil o empresario.

En tal situación, establezco que es el Estado el llamado a proteger el uso debido de los títulos valores, por lo que se debe cumplir lo dictado por la ley, utilizando la letra de cambio y el pagaré solo y exclusivamente para actos de comercio.

En ese ámbito debemos conocer qué es la letra de cambio y qué es el pagaré y cuál es su utilización.

\section{Letra de cambio}

La letra de cambio es "el título de crédito formal y completo que contiene una promesa incondicionada y abstracta de hacer pagar a su vencimiento al tomador o a su orden una suma de dinero en lugar determinado, vinculando solidariamente a todos los que en ella intervienen" (Espinoza, 1995). 
La letra de cambio es un título de mercantil de crédito representativo de dinero, por lo que es una orden incondicional por escrito, de una persona llamada girador a otra llamada girado, firmada por la persona que la otorga, regulada en el Código de Comercio a partir del artículo 702; pero desde el momento en que decimos que es un título mercantil estamos hablando de un título valor de uso exclusivo en la transacción comercial o mercantil.

Pero dicho título valor es mayormente utilizado por personas que no tienen ninguna relación con el comercio, solo por el simple hecho de que en dicho documento se consigna una cantidad determinada o determinable de dinero que debe pagarse a posteriori, por lo que las personas lo han utilizado de una forma tan común que han desvirtuado su naturaleza, o sea, su uso mercantil, ya que cualquier persona que preste dinero lo que usa para garantizar dicha deuda es una letra de cambio, ¿Por qué no hacer un mutuo?, que es el documento idóneo en este tipo de relación civil. Nuevamente insisto en que todos los títulos valores son de uso mercantil, para el tráfico mercantil, para la realización y ejecución de actos de comercio.

\section{El pagaré}

El pagaré, al igual que la letra de cambio, es una promesa de pago escrita que hace una persona, llamada otorgante, a otra, llamada beneficiario, por lo que considero que es un título valor por medio del cual una persona se compromete a pagar una cantidad específica de dinero en una fecha determinada; pero desde el momento que la ley mercantil reconoce al pagaré y le da la calidad de título valor y cosa mercantil, como lo dicta el artículo 5 del Código de Comercio, es del parecer que es un documento solo y exclusivamente para actos de comercio y para ser utilizado por comerciante mercantil o empresario; pero volvemos al mismo problema que atañe nuestro tema: ¿por qué, si el pagaré es un documento mercantil, se le da uso común?, ya que se puede obtener libremente en cualquier librería. Por lo tanto, volvemos al dilema de que si el pagaré es exclusivamente para uso mercantil o no; y siempre para garantizar un pago por un préstamo o un crédito, pudiendo nuevamente utilizarse la figura jurídica civil del mutuo en caso de ser una transacción entre personas naturales.
Cuando establezco la similitud del pagaré con la letra de cambio es por el simple hecho de que la misma ley establece que, en lo que no sean contrarias a su naturaleza, son aplicables al pagaré las normas relativas a la letra de cambio, por lo que las personas también han utilizado este título valor para un uso común.

\section{Conclusiones}

Hay que establecer que en el Código de Comercio mismo no hay una norma donde se establezca la exclusividad de uso mercantil de los títulos valores, por lo que deja abierta la posibilidad de que las personas puedan utilizarlos para cualquier transacción económica.

Tanto la letra de cambio como el pagaré son títulos valores mercantiles, según lo preceptuado por el Código de Comercio, por lo que no deberían de ser de uso público; que cualquier persona pueda usarlos.

\section{Recomendaciones}

Es responsabilidad del Estado hacer valer y cumplir la ley, por lo tanto, debe de velar por que el uso de los documentos llamados títulos valores sean de exclusiva utilidad en el orden mercantil.

Si existiese una relación crediticia entre personas no consideradas comerciantes mercantiles o empresarios, deberían hacer uso de la figura jurídica del mutuo.

\section{Referencias}

Espinoza, J.A. (1995). Temas sobre derecho cartular. Lima: Idemsa.

Fontana, S.P. (1990). Títulos Valores. Lima: Cultural Cuzco, S.A.

Vallejo, J.A. (1989). Teoría General de los Títulos Valores. Lima: Cultural Cuzco, S.A.

Vivante, C. (1936). Tratado de Derecho Mercantil. Madrid: Reus.

Código de Comercio de El Salvador. 